Th-MOF Showing Proton Transformation from $\left[\mathrm{NH}_{2}\left(\mathrm{CH}_{3}\right)_{2}\right]^{+}$to Carboxyl

Group to Enhance Porosity for Selective Adsorption of $\mathrm{D}_{2}$ over $\mathrm{H}_{2}$ and

\title{
Ammonia Capture
}

Li Jun Sun, Ya Lin Fan, Meng Jia Yin, Hui Ping Zhang, Han Feng, Li Juan Guo, and Feng Luo*

Corresponding author: ecitluofeng@163.com 


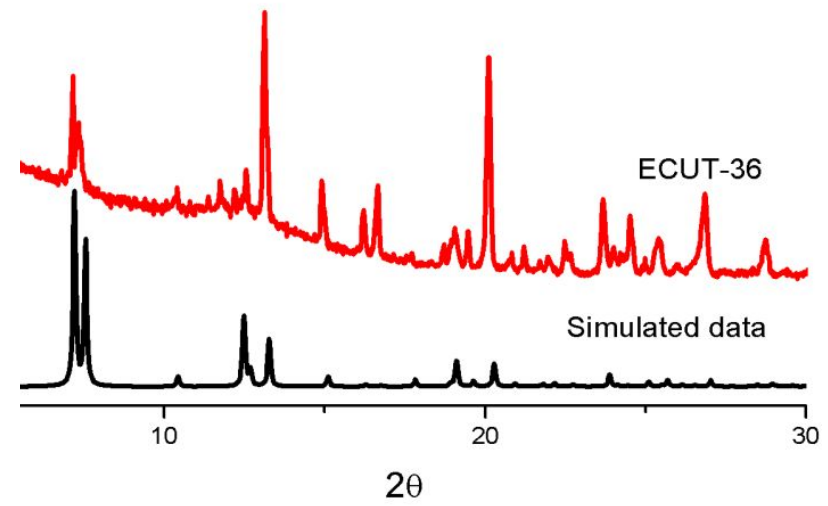

Figure S1. The PXRD patterns of the as-synthesized samples and simulated one from the single crystal data.

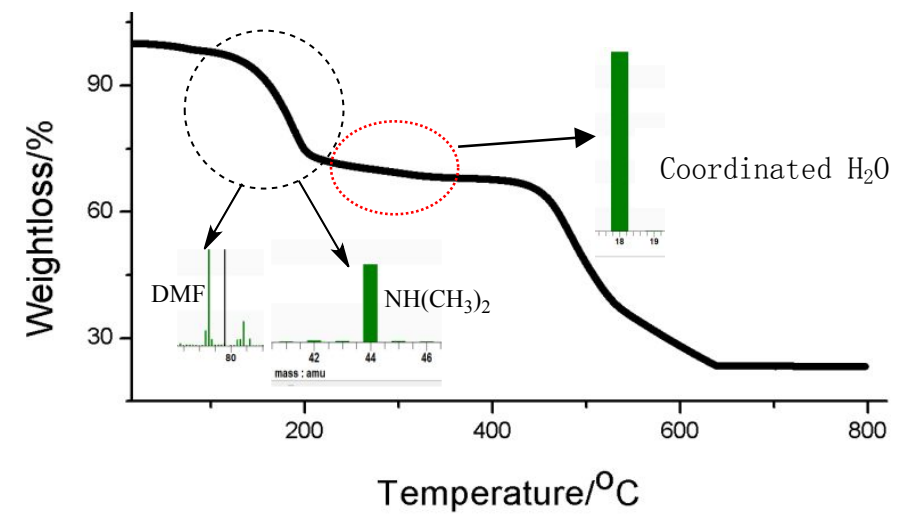

Figure S2. The TG plot of ECUT-36. The release of DMF and $\left[\mathrm{NH}\left(\mathrm{CH}_{3}\right)_{2}\right]$ was traced by MS. 


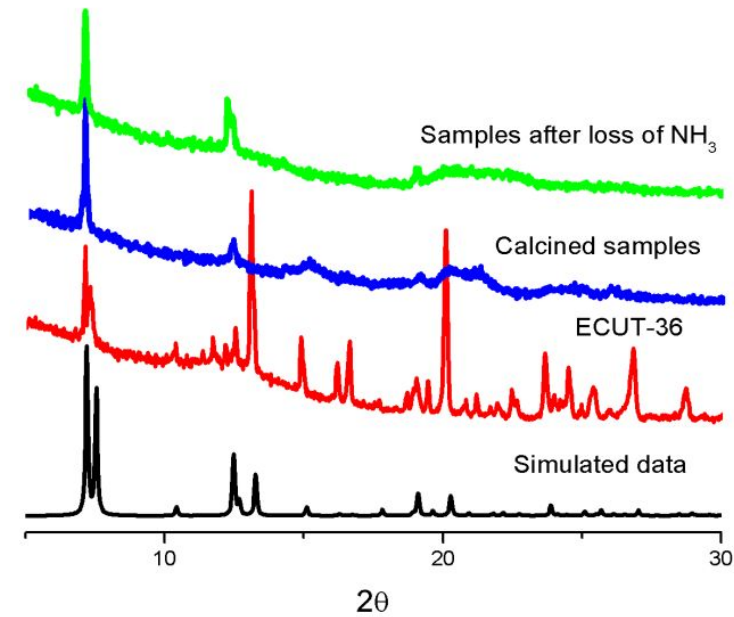

Figure S3. The PXRD patterns of the as-synthesized, calcined samples, the samples after loss of $\mathrm{NH}_{3}$ and simulated one from the single crystal data.

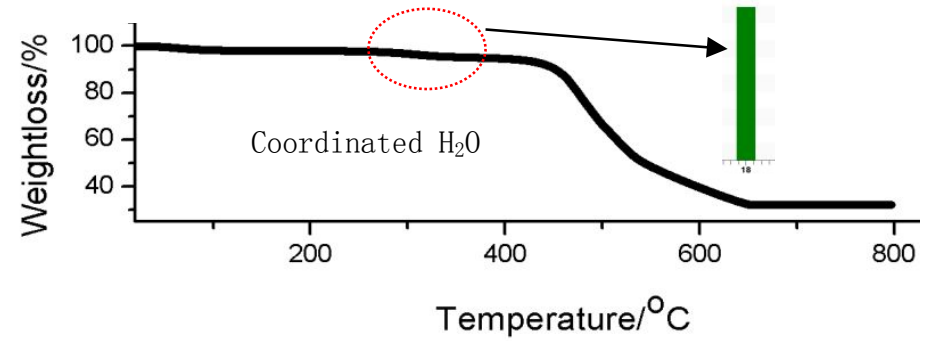

Figure S4. The TG plot of the calcined samples. The highlight is the loss of the terminal coordinated water molecule. 

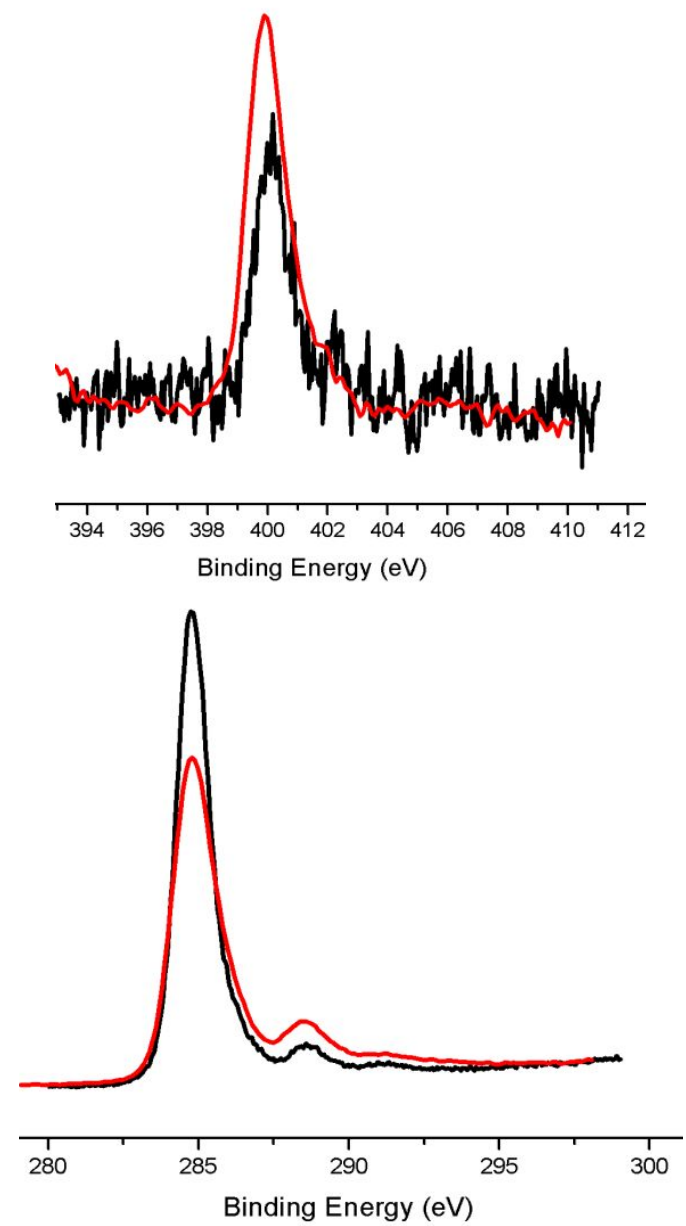

Figure S5. The XPS spectra of N (above) and C (below) element for the as-synthesized (black), calcined samples (red). 


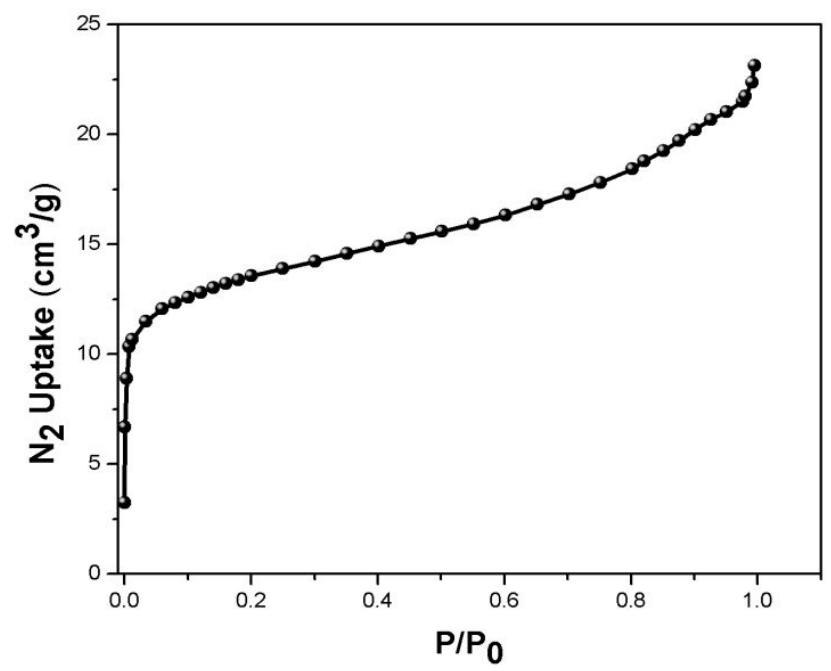

Figure S6. The $\mathrm{N}_{2}$ adsorption at $77 \mathrm{~K}$ for ECUT-36.

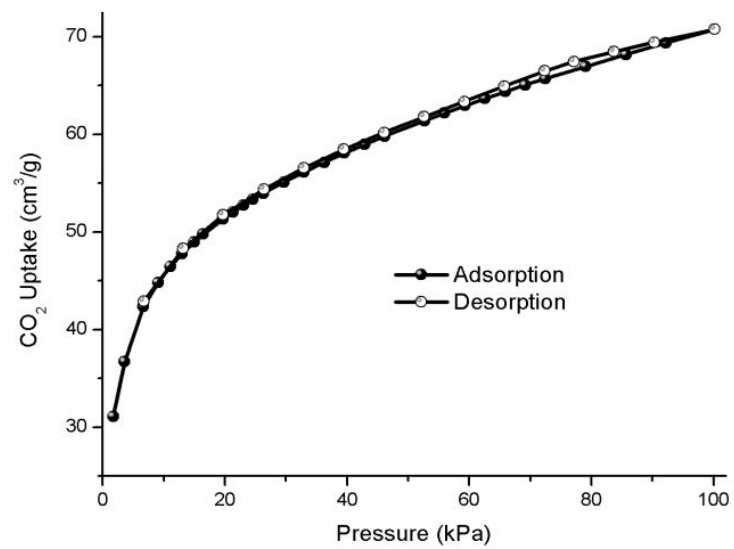

Figure S7. The $\mathrm{CO}_{2}$ adsorption at $195 \mathrm{~K}$ for ECUT-36. 


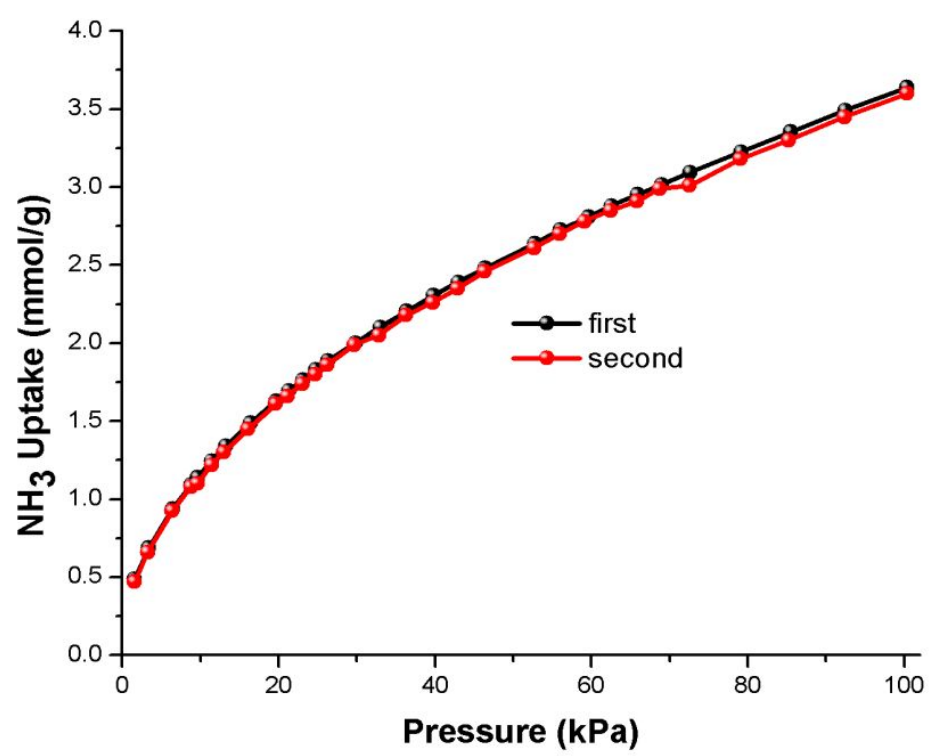

Figure S8. The recycled $\mathrm{NH}_{3}$ uptake for the first and second time. 